\title{
Activity of Tea Tree (Melaleuca alternifolia) Essential Oil against L3 Larvae of Anisakis simplex
}

\author{
Carlota Gómez-Rincón, Elisa Langa, Paula Murillo, Marta Sofía Valero, \\ César Berzosa, and Víctor López
}

Facultad de Ciencias de la Salud, Universidad San Jorge, Campus Universitario Villanueva de Gállego, Autovia A-23 Zaragoza, Huesca, Km 299, 50.830 Villanueva de Gállego, Zaragoza, Spain

Correspondence should be addressed to Carlota Gómez-Rincón; cgomez@usj.es

Received 27 February 2014; Accepted 8 May 2014; Published 25 May 2014

Academic Editor: Gilbert Lefèvre

Copyright (C) 2014 Carlota Gómez-Rincón et al. This is an open access article distributed under the Creative Commons Attribution License, which permits unrestricted use, distribution, and reproduction in any medium, provided the original work is properly cited.

\begin{abstract}
Nematicidal activity of Melaleuca alternifolia essential oil, commonly known as tea tree oil (TTO), was assayed in vitro against L3 larvae of Anisakis simplex. The results showed a mortality of $100 \%$ for concentrations between 7 and $10 \mu \mathrm{L} / \mathrm{mL}$ after $48 \mathrm{~h}$ of incubation, obtaining an LD50 value of $4.53 \mu \mathrm{L} / \mathrm{mL}$ after 24 hours and $4.27 \mu \mathrm{L} / \mathrm{mL}$ after 48 hours. Concentration-dependent inhibition of acetylcholinesterase was observed for tea tree essential oil showing inhibition values of $100 \%$ at $100 \mu \mathrm{L} / \mathrm{mL}$. This fact suggests that TTO may act as an AChE inhibitor. Terpinen-4-ol was discarded as main larvicide compound as it did not show larvicidal or anticholinesterase activity. The data obtained suggest that the essential oil of Melaleuca alternifolia may have a great therapeutic potential for the treatment of human anisakiasis.
\end{abstract}

\section{Introduction}

In the last years, the implication of Anisakis simplex in gastric, intestinal, and allergic clinical disorders has significantly increased [1]. More than $90 \%$ of anisakiasis cases are reported in Japan [2]. However, the high human consumption together with the high Anisakis prevalence in seafood from coastal areas of Europa $[3,4]$ suggests that anisakiasis may be an underdiagnosed illness [1-3, 5-7].

Larval endoscopic extraction is the preferred treatment of gastric and intestinal anisakiasis but if the larva is not accessible surgical treatment should be necessary [1]. Pharmacological treatments with antibiotics, anticholinergics, and/or corticosteroids have been occasionally used but their efficacy remains unclear $[6,8,9]$. On the other hand, some studies have suggested that treatment with nematicides as albendazole may constitute an effective therapy [10-13]. However, the worldwide development of resistance to chemical anthelmintic drugs [14] and a current social demand for natural therapeutic products has increased the search for new biocide molecules. Plant products are the basis of traditional medicine and the only health resource available in many communities from developing countries. Otherwise, several plant essential oils and their derived compound have shown biocidal activity against Anisakis spp. [15-19].

Tea tree oil (TTO) is the essential oil obtained by hydrodistillation from Melaleuca alternifolia, a species native from New South Wales, Australia [20]. Tea tree oil is a natural product derived from the Australian native plant Melaleuca alternifolia that has shown multiple biological activities such as anti-inflammatory, antitumoral, and biocidal properties [21]. Tea tree oil is an effective bactericide [22], fungicide [23], antiviral [24], and insecticidal agent [25, 26]. Furthermore, several studies have demonstrated its effectiveness against protozoa parasites as Leishmania major or Trypanosoma brucei [27]. But there is no evidence of the effect that this substance might have on parasite nematodes.

Many nematicides act through an inhibition of parasite motility. The motility blockade causes inability to remain on the host favouring the parasite elimination. One of the mechanisms affecting this parasite function is the effect on acetylcholine and/or acetylcholinesterase activity. Levamisole acts as an agonist on nicotinic acetylcholine receptors 
at the nematode neuromuscular junction, leading to sustained neuromuscular depolarization and spastic paralysis $[28,29]$. In this line, Mills et al. [30] propose that the pediculicide effect of TTO could be due to, at least in part, anticholinesterase activity of its two main components terpinen-4-ol and 1,8 cineole.

The aim of the present study was to analyze the activity of tea tree essential oil and its main component terpinen-4-ol against Anisakis simplex third stage larvae (L3) and to explore the inhibition of acetylcholinesterase as possible mechanism of action.

\section{Materials and Methods}

2.1. Essential Oil. Tea tree essential oil was supplied by Pranarôm. Although the essential oils are chemically characterized by Pranarôm International, they were analysed by GC-MS on an Agilent 6890N Network GC system coupled to a 5973 Network Mass Selective Detector, accelerating voltage $-69.9 \mathrm{eV}$, recoding masses of 35.00-400.00. GC conditions are as follows: injector temperature: $150^{\circ} \mathrm{C}$; temperature programme: starts from $50^{\circ} \mathrm{C}, 20^{\circ} \mathrm{C} / \mathrm{min}$ to $300^{\circ} \mathrm{C}$; column: HP5MS (5\% phenylmethylsiloxane) capillary, $30.0 \mathrm{~m} \times$ $250 \mu \mathrm{L} \times 0.25 \mu \mathrm{m}$ nominal; carrier gas: helium at $1.0 \mathrm{~mL} / \mathrm{min}$. A NIST library was used for comparison of MS data.

2.2. In Vitro Larvicidal Activity. Anisakis simplex L3 was isolated from the intermediary host Micromesistius poutassou (blue whiting) purchased from several fish markets in Zaragoza. Worms were washed several times with sterile solution of $0.9 \% \mathrm{NaCl}$ and identified under light microscope according to morphological features [31, 32]. Only intact Anisakis simplex s.l, L3 with length $>2.0 \mathrm{~cm}$ were used. Ten larvae were introduced in each well of polystyrene plates with $2 \mathrm{~mL}$ of sterile saline solution containing different concentration of the test solutions. The final concentrations of Melaleuca alternifolia essential oil were: 10, 7, 5, 4, 3, 2, 1, and $0.5 \mu \mathrm{g} / \mathrm{mL}$. For terpinel-4-ol the final concentrations tested were $0.1,1$, and $10 \mu \mathrm{g} / \mathrm{mL}$. The parasites were incubated at $37^{\circ} \mathrm{C}$ in $5 \% \mathrm{CO}_{2}$. Each dilution, together with saline solution negative control, was tested by triplicates on three different days. Levamisole $(100 \mu \mathrm{L} / \mathrm{mL})$ was used as the reference antiparasitic drug. Larvae were examined at $24 \mathrm{~h}$ and $48 \mathrm{~h}$ under microscope and immobile L3 were considered dead. In order to evaluate the biocidal activity of the samples, an average mortality was determined. LC50 was calculated using nonlinear regression (GraphPad Prism 5).

2.3. Inhibition of Acetylcholinesterase. The inhibition of acetylcholinesterase (AChE) was determined by the Ellman method [33] with some modifications. The AChE activity was measured using a 96-microplate, each well containing $25 \mu \mathrm{L}$ of $15 \mathrm{mM}$ ATCI in Millipore water, $125 \mu \mathrm{L}$ of $3 \mathrm{mM}$ DTNB in buffer C $(50 \mathrm{mM}$ Tris- $\mathrm{HCl}, \mathrm{pH} 8,0.1 \mathrm{M} \mathrm{NaCl}$, $0.02 \mathrm{M} \mathrm{MgCl}_{2} 6 \mathrm{H}_{2} \mathrm{O}$ ), $50 \mu \mathrm{L}$ buffer B (50 mM Tris- $\mathrm{HCl}, \mathrm{pH}$ $8,0.1 \%$ bovine serum), and $25 \mu \mathrm{L}$ of test compound. Every concentration tested of TTO $(0.1,1,10$, and $100 \mu \mathrm{L} / \mathrm{mL})$, terpinen-4-ol $(0.1 ; 1$ and $10 \mu \mathrm{L} / \mathrm{mL})$, and Levamisole $(0.1$,
TABLE 1: Composition of Melaleuca alternifolia essential oil (\% v/w).

\begin{tabular}{lc}
\hline Compound & $\%$ \\
\hline alpha-Pinene & 3.0 \\
alpha-Terpinene & 10.3 \\
Para-cymene & 5.9 \\
Eucalyptol (1,8 cineole) & 3.6 \\
gamma-terpinene & 22.5 \\
Terpinolene & 3.8 \\
Terpinen-4-ol & 46.9 \\
alpha-Terpineol & 3.8 \\
\hline
\end{tabular}

1,10 , and $100 \mu \mathrm{L} / \mathrm{mL}$ ) was diluted in DMSO and tested in triplicates. Then, $25 \mu \mathrm{L} 0.22 \mathrm{U} / \mathrm{mL}$ AChE was added and the absorbance was measured eight times every $13 \mathrm{~s}$ at $405 \mathrm{~nm}$.

2.4. Statistical Analyses. Data were subjected to analysis of variance, and mean comparison was performed by one-way ANOVA plus Scheffé multiple comparisons $(P \leq 0.05)$. The statistical analysis was performed using PASW Statistics 18 program.

\section{Results}

3.1. Composition of Melaleuca alternifolia Essential Oil. Eight main compounds were detected in the essential oil analyzed by GC-MS (Table 1). The compounds and their abundance are consistent with the chemical characterization provided by Pranarôm International.

3.2. In Vitro Larvicidal Activity. Tea tree essential oil showed a significant dose-dependent lethal effect on Anisakis simplex L3 $(P<0.05)$ (Table 2$)$. Concentrations of $5 \mu \mathrm{L} / \mathrm{mL}$ and above impair the larvae survival after $24 \mathrm{~h}$ exposure $(P \leq 0.05)$. Otherwise, $4 \mu \mathrm{L} / \mathrm{mL}$ of TTO required $48 \mathrm{~h}$ to reduce larval vitality. The most effective concentrations were $10 \mu \mathrm{L} / \mathrm{mL}$, which showed a total lethal effect at $24 \mathrm{~h}$ and $7 \mu \mathrm{L} / \mathrm{mL}$ that caused $93 \%$ and $100 \%$ mortality after $24 \mathrm{~h}$ and $48 \mathrm{~h}$ incubation. Terpinen-4-ol did not show any larvicide effect at tested concentration. Levamisole, an anthelmintic drug used as positive control, was highly effective causing a 100\% larval mortality after $24 \mathrm{~h}$.

The logistic regression of data revealed a dose-response effect for the TTO that showed $\mathrm{LD}_{50}$ values of 4.53 and $4.27 \mu \mathrm{L} / \mathrm{mL}$ after 24 and $48 \mathrm{~h}$ (Figure 1).

3.3. Inhibition of Acetylcholinesterase Assay. Concentrationdependent inhibition of AChE was observed for tea tree essential oil and levamisole (Table 3). TTO showed inhibition values of $100 \%$ at $100 \mu \mathrm{L} / \mathrm{mL}$ and were significantly more effective than the AChE inhibitor levamisole at the same concentration $(P \leq 0.05)$. However, terpinen-4-ol, the main component of TTO, did not show inhibition of AChE at the tested concentrations. 
TABLE 2: In vitro effect of Melaleuca alternifolia essential oil and terpinen-4-ol on L3 of Anisakis simplex survival. Results are expressed as average mortality \pm standard deviation.

\begin{tabular}{|c|c|c|c|}
\hline \multirow{3}{*}{ Compound } & \multirow{3}{*}{ Concentration $(\mu \mathrm{L} / \mathrm{mL})$} & \multicolumn{2}{|c|}{ Average mortality (\%) } \\
\hline & & \multicolumn{2}{|c|}{$(n=90 \mathrm{~L} 3)$} \\
\hline & & $24 \mathrm{~h}$ & $48 \mathrm{~h}$ \\
\hline Control & & $3.3 \pm 10$ & $5.6 \pm 6.7$ \\
\hline \multirow{8}{*}{ Melaleuca alternifolia $\mathrm{EO}$} & 10 & $100^{*}$ & $100^{*}$ \\
\hline & 7 & $93 \pm 5.8^{*}$ & $100^{*}$ \\
\hline & 5 & $52.3 \pm 38.4^{*}$ & $81.1 \pm 24.2^{*}$ \\
\hline & 4 & $30 \pm 20.9$ & $38.3 \pm 11.7^{*}$ \\
\hline & 3 & $18.3 \pm 20.4$ & $21.7 \pm 17.2$ \\
\hline & 2 & $10 \pm 15.5$ & $5 \pm 8.4$ \\
\hline & 1 & $7.7 \pm 10.9$ & $10 \pm 13.2$ \\
\hline & 0.5 & $2.2 \pm 6.8$ & $2.2 \pm 6.8$ \\
\hline \multirow{3}{*}{ Terpinen-4-ol } & 10 & 0 & 0 \\
\hline & 1 & 0 & 0 \\
\hline & 0.1 & 0 & 0 \\
\hline
\end{tabular}

${ }^{*}$ Indicates values that differ from the control $(P<0.05)$.

Levamisole was used as positive control reference drug at the dose of $100 \mu \mathrm{g} / \mathrm{mL}$ obtaining $100 \%$ of mortality after $24 \mathrm{~h}$. $n$ : total number of $\mathrm{L} 3$ used to test every concentration.

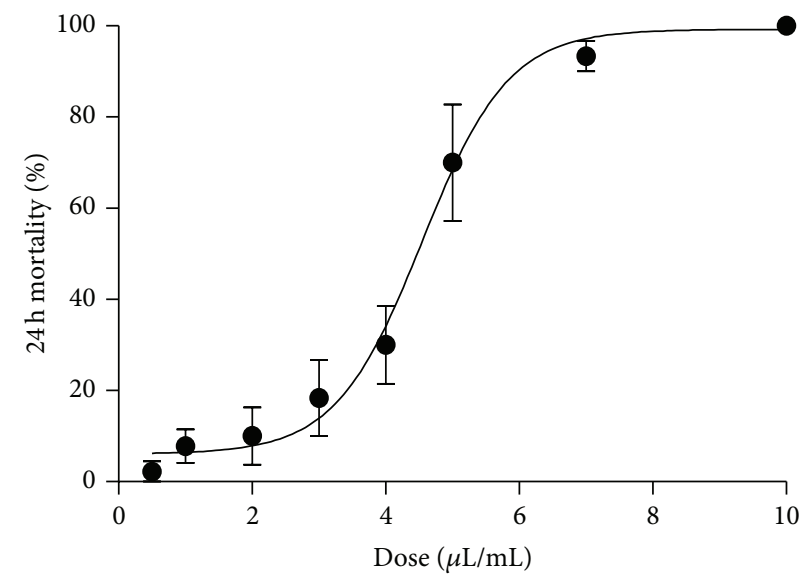

(a)

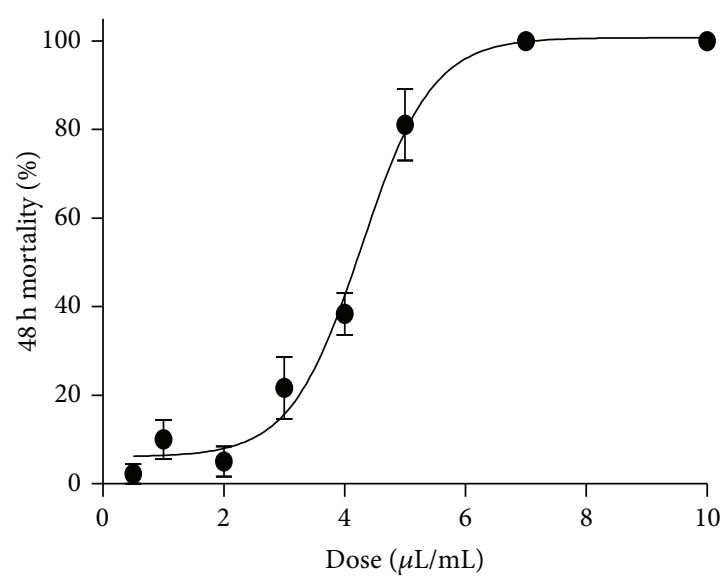

(b)

FIGURE 1: Dose-response effect of Melaleuca alternifolia essential oil after 24 and $48 \mathrm{~h}$ of exposure.

\section{Discussion}

The increasing worldwide incidence of anisakiasis together with the lack of effective pharmacological treatments warrants the search for new active molecules. Although in most cases anisakiosis resolved spontaneously, the severity of potential complications such as peritonitis or intestinal wall perforations, frequently surgical treatments are required [34]. On the other hand, in the current context of economic crisis, optimization of health resources is essential. Therefore the search for less invasive and expensive sanitary interventions should be a research priority in health sciences. In that sense, the use of essential oils and natural products could provide a noninvasive, inexpensive, and effective treatment for human anisakiasis.

In recent years, the biocidal activity against Anisakis L3 of several essential oils and some of its components has been studied. Romero et al. [19] demonstrated that $125 \mu \mathrm{g} / \mathrm{mL}$ of Matricaria chamomilla essential oil induced $100 \%$ larval mortality after $4 \mathrm{~h}$ in vitro and reduced the pathogenic effects in experimentally infected rats. The results obtained in our study show that TTO was effective, obtaining significant larvicidal effect at doses over $4 \mu \mathrm{L} / \mathrm{mL}$. The maximal concentration tested $(10 \mu \mathrm{L} / \mathrm{mL})$ was $100 \%$ lethal at $24 \mathrm{~h}$. Similarly, at a concentration of $7 \mu \mathrm{L} / \mathrm{mL}$, larvicidal activity was $93 \%$ at $24 \mathrm{~h}$ and $100 \%$ after $48 \mathrm{~h}$ of essential oil 
TABLE 3: Percentage of acetylcholinesterase inhibition by Melaleuca alternifolia essential oil, terpinen-4-ol, and levamisole.

\begin{tabular}{lcc}
\hline Compound & Concentration $(\mu \mathrm{L} / \mathrm{mL})$ & \% Inhibition \\
\hline Melaleuca alternifolia & 0.1 & $19.8 \pm 2.9$ \\
essential oil & 1 & $31.9 \pm 26.5$ \\
& 10 & $96.5 \pm 18.9$ \\
& 100 & 100 \\
Terpinen-4-ol & 0.1 & 0 \\
& 1 & 0 \\
Levamisole & 10 & 0 \\
& 1 & $24.0 \pm 5.9$ \\
& 10 & $85.2 \pm 2.1$ \\
\hline
\end{tabular}

exposure. Observed mortality for other concentrations was low; however, mortality percentages were $52 \%$ and $83 \%$ after 24 and $48 \mathrm{~h}$ of exposure to $5 \mu \mathrm{L} / \mathrm{mL}$ of EO.

Many studies have demonstrated the potent biocide effect of TTO. Many bacteria are susceptible to concentrations of $1 \%$ or less even against antibiotic-resistant strains [21]. TTO has also a fungicidal activity at concentrations ranging from 0.12 to $2 \%$ against yeast and dermatophytes [23, 35]. Although there are no previous references regarding the TTO LD50 against nematodes, the values obtained in our study $\left(\mathrm{LD} 50_{24 \mathrm{~h}}=4.53 \mu \mathrm{L} / \mathrm{mL}\right.$ and $\left.\mathrm{LD}_{50} 0_{48 \mathrm{~h}}=4.14 \mu \mathrm{L} / \mathrm{mL}\right)$ suggest that TTO could be an effective nematicide.

Essential oils are complex mixtures of compounds from natural origin, among which the terpenes have been largely studied and have shown useful pharmaceutical properties. Several monoterpenes as carvacrol, geraniol, or citronellol (monoterpenes) [19] and sesquiterpenes as nerolidol or farnesol [36] show a high potential against Anisakis L3. The main component of the essential oil obtained from tea tree is terpinen-4-ol [37]. Different authors suggest that this monoterpene is responsible, at least in part, for the antiprotozoal [27] and bactericidal [38] effects of the tea tree. Furthermore, recent studies suggest that terpinen-4-ol inhibits the motility of the plant parasitic nematode Meloidogyne incognita [39]. However, the larvicidal effect observed in our study cannot be associated with this compound since we did not observe any effect on Anisakis larvae. Therefore, we can deduce that the effect could be related to other compounds. It seems unlikely that alpha-terpinene and 1,8 cineole are responsible for the antiparasitic activity, at least individually, since they are inactive at high concentration against the plant nematode Meloidogyne incognita [39]. Otherwise, a possible candidate may be alpha-pinene ( $3 \%$ concentration in our essential oil), whose activity has been recently demonstrated in vitro and in vivo against Anisakis spp. [17]. However, due to the chemical complexity of essential oils, it should be noted that many of their properties are due to the synergistic or complementary effects of several components.

In this work we have also evaluated the AChE inhibition as a possible mechanism of action involved in the TTO nematicidal effect. Data showed that, at the same concentrations, TTO was a more effective AChE inhibitor than levamisole. These differences could be due to the fact that both drugs block the enzyme activity at different levels. Levamisole is a potent cholinergic agonist that binds preferentially to L-subtype nicotinic acetylcholine receptors in body-wall muscle causing hypercontracted paralysis, usually followed by relaxation and death $[28,29,40,41]$. However, our results suggest that levamisole also has a moderate direct inhibitory effect on the enzyme. In this sense, tea tree essential oil seems to have a direct effect on the enzyme activity which is completely blocked at concentrations of $100 \mu \mathrm{L} / \mathrm{mL}$. These results suggest that inhibition of AChE could be a possible TTO mechanism of action against Anisakis. This hypothesis is consistent with the TTO anticholinesterase activity observed by Mills et al. [30] who proposed the competitive inhibition of AChE by 1,8 cineole and terpinen-4-ol to explain the TTO insecticidal effect. However, the IC50 values were $10.30 \mathrm{mM}$ and $0.04 \mathrm{mM}$ for terpinen-4-ol and 1,8 cineole, respectively, concluding that both compounds are weak inhibitors of the activity of the enzyme. In our study, even though the used concentration values were similar to those used by Mills et al. [30], terpinen-4-ol did not show anticholinesterase activity. This fact, together with the absence of larvicidal effect in vitro, leads us to discard terpinen-4-ol as main active compound against Anisakis L3. However, several studies suggest that the antimicrobial activity of TTO is attributed mainly to terpinen-4-ol [38]. For this reason, we are unable to discard that this compound has an active role in anthelmintic activity, as it may contribute indirectly or synergistically to the activity of other components of TTO.

Due to its chemical complexity, it is difficult to establish the mechanism of action involved in the biological effects of the essential oils. Therefore, the anticholinesterase effect observed in our study might be only partially responsible for the observed anthelmintic activity. It has been demonstrated that the interaction between the components of the TTO and cell membranes induces biochemical changes causing structural and functional cell integrity loss [21]. To our knowledge, there are no data about the effect of TTO on Anisakis simplex although recent studies suggest that essential oils or their constituents could cause alterations in the cuticle, muscle cells, and digestive system of L3. These effects would unleash the parasite death $[16,42]$ and, moreover, reduce the larval infectivity and their pathogenic effect in vivo [19].

Tea tree essential oil has long been used topically as an antiseptic; however, there are few data about its oral safety. Published data indicated that TTO can be toxic if ingested in higher doses [43]. In vivo rat models toxicity studies showed LD50 values of $1.9-2.6 \mathrm{~mL} / \mathrm{kg}$ [44]. Recent studies confirmed these data and revealed cytotoxic effects on human oral epithelial cells at concentrations of $500 \mu \mathrm{L} / \mathrm{mL}$ [45]. Our in vitro experiments showed a high effectiveness of TTO against Anisakis L3 at lower concentrations suggesting that this molecule could be an effective nematicide. However, these results must be supported by in vivo studies to ensure the efficacy and safety of essential oil of tea tree in treating clinical anisakiasis. 


\section{Conclusions}

According to our results Melaleuca alternifolia essential oil showed a remarkable in vitro nematicidal effect for concentrations between 7 and $10 \mu \mathrm{L} / \mathrm{mL}$. Concentration-dependent inhibition of acetylcholinesterase was observed, suggesting that TTO may act as an AChE inhibitor. Terpinen-4-ol was discarded as main larvicide compound. Data obtained suggest that the essential oil of Melaleuca alternifolia may be a therapeutic tool for human anisakiasis.

\section{Conflict of Interests}

The authors declare that there is no conflict of interests regarding the publication of this paper.

\section{Acknowledgments}

Project is carried out by Research Group GIMACES E02, Grupo Consolidado de Investigación Aplicada, Gobierno de Aragón, supported by Gobierno de Aragón and Fondo Social Europeo "Construyendo Europa desde Aragón."

\section{References}

[1] N. S. Hochberg and D. H. Hamer, "Anisakidosis: perils of the deep," Clinical Infectious Diseases, vol. 51, no. 7, pp. 806-812, 2010.

[2] M. T. Audicana and M. W. Kennedy, "Anisakis simplex: from obscure infectious worm to inducer of immune hypersensitivity," Clinical Microbiology Reviews, vol. 21, no. 2, pp. 360-379, 2008.

[3] E. Madrid, M. T. Galán-Puchades, and M. V. Fuentes, "Risk analysis of human anisakidosis through the consumption of the blue whiting, micromesistius poutassou, sold at Spanish supermarkets," Foodborne Pathogens and Disease, vol. 9, no. 10, pp. 934-938, 2012.

[4] F. J. Rello, F. J. Adroher, R. Benítez, and A. Valero, “The fishing area as a possible indicator of the infection by anisakids in anchovies (Engraulis encrasicolus) from southwestern Europe," International Journal of Food Microbiology, vol. 129, no. 3, pp. 277-281, 2009.

[5] J. Y. Chai, K. D. Murrell, and A. J. Lymbery, "Fish-borne parasitic zoonoses: status and issues," International Journal for Parasitology, vol. 35, no. 11-12, pp. 1233-1254, 2005.

[6] L. Ramos, C. Alonso, M. Guilarte, J. Vilaseca, J. Santos, and J. R. Malagelada, "Anisakis simplex-induced small bowel obstruction after fish ingestion: preliminary evidence for response to parenteral corticosteroids," Clinical Gastroenterology and Hepatology, vol. 3, no. 7, pp. 667-671, 2005.

[7] I. Mladineo, V. Poljak, V. Martínez-Sernández, and F. M. Ubeira, "Anti-anisakis IgE seroprevalence in the healthy Croatian Coastal Population and associated risk factors," PLoS Neglected Tropical Diseases, vol. 8, no. 2, Article ID e2673, 2014.

[8] T. Matsui, M. Iida, and M. Murakami, "Intestinal anisakiasis: clinical and radiologic features," Radiology, vol. 157, no. 2, pp. 299-302, 1985.

[9] M. A. M. Verhamme and C. H. R. Ramboer, "Anisakiasis caused by herring in vinegar: a little known medical problem," Gut, vol. 29, no. 6, pp. 843-847, 1988.
[10] J.-F. Magnaval, A. Berry, and M. Nadrigny, "Anaphylactic shock revealing anisakiasis," Presse Medicale, vol. 31, no. 28, pp. 13091311, 2002.

[11] D. A. J. Moore, R. W. A. Girdwood, and P. L. Chiodini, "Treatment of anisakiasis with albendazole," The Lancet, vol. 360, no. 9326, p. 54, 2002.

[12] E. Pacios, J. Arias-Diaz, J. Zuloaga, J. Gonzalez-Armengol, P. Villarroel, and J. L. Balibrea, "Albendazole for the treatment of Anisakiasis ileus," Clinical Infectious Diseases, vol. 41, no. 12, pp. 1825-1826, 2005.

[13] J. Arias-Diaz, J. Zuloaga, E. Vara, J. Balibrea, and J. L. Balibrea, "Efficacy of albendazole against Anisakis simplex larvae in vitro," Digestive and Liver Disease, vol. 38, no. 1, pp. 24-26, 2006.

[14] A. K. Rana and S. Misra-Bhattacharya, "Current drug targets for helminthic diseases," Parasitology Research, vol. 112, no. 5, pp. 1819-1831, 2013.

[15] C. Goto, S. Kasuya, K. Koga, H. Ohtoma, and N. Kagei, "Lethal efficacy of extract from zingiber-officinale (traditional chinese medicine) or 6 -shogaol and 6 -gingerol in anisakis larvae invitro," Parasitology Research, vol. 76, no. 8, pp. 653-656, 1990.

[16] I. Hierro, A. Valero, and M. C. Navarro, "In vivo larvicidal activity of monoterpenic derivatives from aromatic plants against L3 larvae of Anisakis simplex s.l," Phytomedicine, vol. 13, no. 7, pp. 527-531, 2006.

[17] M. C. Navarro, M. A. Noguera, M. C. Romero, M. P. Montilla, J. M. González de Selgas, and A. Valero, "Anisakis simplex s.l.: Larvicidal activity of various monoterpenic derivatives of natural origin against L3 larvae in vitro and in vivo," Experimental Parasitology, vol. 120, no. 4, pp. 295-299, 2008.

[18] R. J. Lin, C. Y. Chen, J. D. Lee, C. M. Lu, L. Y. Chung, and C. M. Yen, "Larvicidal constituents of Zingiber officinale (Ginger) against Anisakis simplex," Planta Medica, vol. 76, no. 16, pp. $1852-1858,2010$.

[19] M. D. C. Romero, A. Valero, J. Martín-Sánchez, and M. C. Navarro-Moll, "Activity of Matricaria chamomilla essential oil against anisakiasis," Phytomedicine, vol. 19, no. 6, pp. 520-523, 2012.

[20] G. Swords and G. L. K. Hunter, "Composition of Australian tea tree oil (Melaleuca alternifolia)," Journal of Agricultural and Food Chemistry, vol. 26, no. 3, pp. 734-737, 1978.

[21] C. F. Carson, K. A. Hammer, and T. V. Riley, "Melaleuca alternifolia (tea tree) oil: a review of antimicrobial and other medicinal properties," Clinical Microbiology Reviews, vol. 19, no. 1, pp. 50-62, 2006.

[22] C. F. Carson and T. V. Riley, "Antimicrobial activity of the essential oil of Melaleuca alternifolia," Letters in Applied Microbiology, vol. 16, no. 2, pp. 49-55, 1993.

[23] F. D. D’Auria, L. Laino, V. Strippoli et al., "In vitro activity of tea tree oil against Candida albicans mycelial conversion and other pathogenic fungi," Journal of Chemotherapy, vol. 13, no. 4, pp. 377-383, 2001.

[24] P. Schnitzler, K. Schön, and J. Reichling, "Antiviral activity of Australian tea tree oil and eucalyptus oil against herpes simplex virus in cell culture," Pharmazie, vol. 56, no. 4, pp. 343-347, 2001.

[25] J. Heukelbach, D. V. Canyon, F. A. Oliveira, R. Muller, and R. Speare, "In vitro efficacy of over-the-counter botanical pediculicides against the head louse Pediculus humanus var capitis based on a stringent standard for mortality assessment," Medical and Veterinary Entomology, vol. 22, no. 3, pp. 264-272, 2008. 
[26] E. di Campli, S. di Bartolomeo, P. Delli Pizzi et al., "Activity of tea tree oil and nerolidol alone or in combination against Pediculus capitis (head lice) and its eggs," Parasitology Research, vol. 111, no. 5, pp. 1985-1992, 2012.

[27] J. Mikus, M. Harkenthal, D. Steverding, and J. Reichling, "In vitro effect of essential oils and isolated mono- and sesquiterpenes on Leishmania major and Trypanosoma brucei," Planta Medica, vol. 66, no. 4, pp. 366-368, 2000.

[28] R. J. Martin and A. P. Robertson, "Mode of action of levamisole and pyrantel, anthelmintic resistance, E153 and Q57," Parasitology, vol. 134, no. 8, pp. 1093-1104, 2007.

[29] R. J. Martin, S. Verma, M. Levandoski et al., "Drug resistance and neurotransmitter receptors of nematodes: recent studies on the mode of action of levamisole," Parasitology, vol. 131, pp. S71S84, 2005.

[30] C. Mills, B. J. Cleary, J. F. Gilmer, and J. J. Walsh, "Inhibition of acetylcholinesterase by Tea Tree oil," Journal of Pharmacy and Pharmacology, vol. 56, no. 3, pp. 375-379, 2004.

[31] G. Hartwich, "Keys to genera of the Ascaridoidea," in CIH Keys to the nemaTode Parasites of Vertebrates, R. C. Anderson, A. G. Chabaud, and S. Wilmott, Eds., vol. 2, pp. 1-15, Commonwealth Agricultural Bureaux, Slough, UK, 1974.

[32] J. A. Petter and C. Maillard, "Larves d'Ascarides parasites de Poissons en Méditerranée occidentale," Bulletin du Museum National d'Histoire Naturelle, vol. 10, pp. 347-369, 1988.

[33] G. L. Ellman, K. D. Courtney, V. Andres Jr., and R. M. Featherstone, "A new and rapid colorimetric determination of acetylcholinesterase activity," Biochemical Pharmacology, vol. 7, no. 2, p. 88, 1961.

[34] M. Pellegrini, R. Occhini, G. Tordini, C. Vindigni, S. Russo, and G. Marzocca, "Acute abdomen due to small bowel anisakiasis," Digestive and Liver Disease, vol. 37, no. 1, pp. 65-67, 2005.

[35] P. Nenoff, U. F. Haustein, and W. Brandt, "Antifungal activity of the essential oil of Melaleuca alternifolia (tea tree oil) against pathogenic fungi in vitro," Skin Pharmacology, vol. 9, pp. 388394, 1996.

[36] M. C. Navarro-Moll, M. C. Romero, M. P. Montilla, and A. Valero, "In vitro and in vivo activity of three sesquiterpenes against L3 larvae of Anisakis type I," Experimental Parasitology, vol. 127, no. 2, pp. 405-408, 2011.

[37] L. E. Homer, D. N. Leach, D. Lea, L. Slade Lee, R. J. Henry, and P. R. Baverstock, "Natural variation in the essential oil content of Melaleuca alternifolia Cheel (Myrtaceae)," Biochemical Systematics and Ecology, vol. 28, no. 4, pp. 367-382, 2000.

[38] C. F. Carson, B. J. Mee, and T. V. Riley, "Mechanism of action of Melaleuca alternifolia (tea tree) oil on Staphylococcus aureus determined by time-kill, lysis, leakage, and salt tolerance assays and electron microscopy," Antimicrobial Agents and Chemotherapy, vol. 46, no. 6, pp. 1914-1920, 2002.

[39] S. Echeverrigaray, J. Zacaria, and R. Beltrão, "Nematicidal activity of monoterpenoids against the root-knot nematode meloidogyne incognita," Phytopathology, vol. 100, no. 2, pp. 199203, 2010.

[40] J. A. Lewis, C. H. Wu, H. Berg, and J. H. Levine, "The genetics of levamisole resistance in the nematode Caenorhabditis elegans," Genetics, vol. 95, no. 4, pp. 905-928, 1980.

[41] I. D. Harrow and K. A. F. Gration, "Mode of action of the anthelmintics morantel, pyrantel and levamisole on muscle-cell membrane of the nematode ascaris-suum," Pesticide Science, vol. 16, pp. 662-672, 1985.
[42] I. Hierro, A. Valero, P. Pérez et al., "Action of different monoterpenic compounds against Anisakis simplex s.l. L3 larvae," Phytomedicine, vol. 11, no. 1, pp. 77-82, 2004.

[43] K. A. Hammer, C. F. Carson, T. V. Riley, and J. B. Nielsen, "A review of the toxicity of Melaleuca alternifolia (tea tree) oil," Food and Chemical Toxicology, vol. 44, no. 5, pp. 616-625, 2006.

[44] M. Russell, “Toxicology of tea tree oil," in Tea Tree: the Genus Malaleuca, I. Sputhwell and R. Lowe, Eds., vol. 9, pp. 191-201, Harwood Academic Publishers, Amsterdam, The Netherlands, 1999.

[45] G. Ramage, S. Milligan, D. F. Lappin et al., "Antifungal, cytotoxic, and immunomodulatory properties of tea tree oil and its derivative components: potential role in management of oral candidosis in cancer patients," Frontiers in Microbiology, vol. 3, article 220, 2012. 

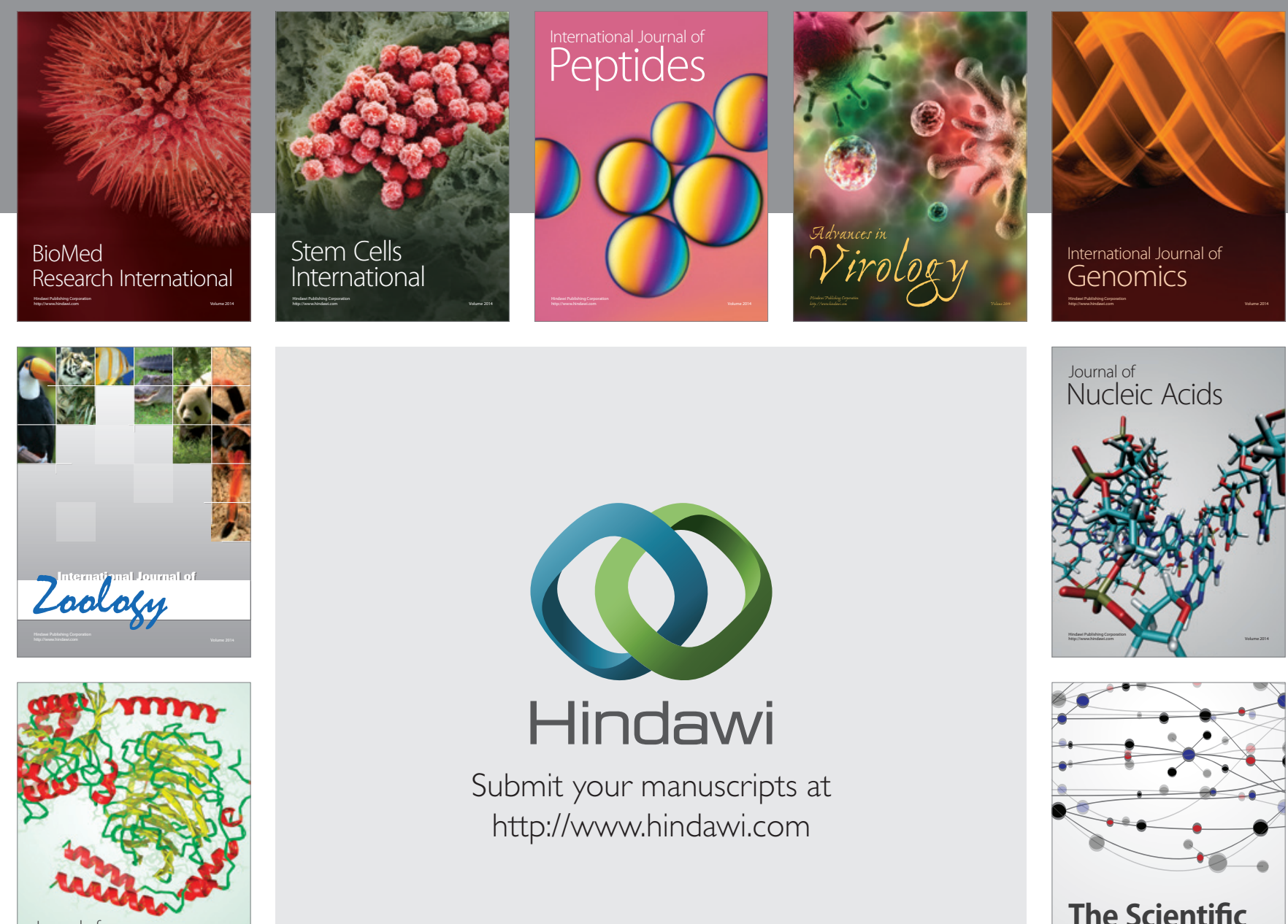

Submit your manuscripts at

http://www.hindawi.com

Journal of
Signal Transduction
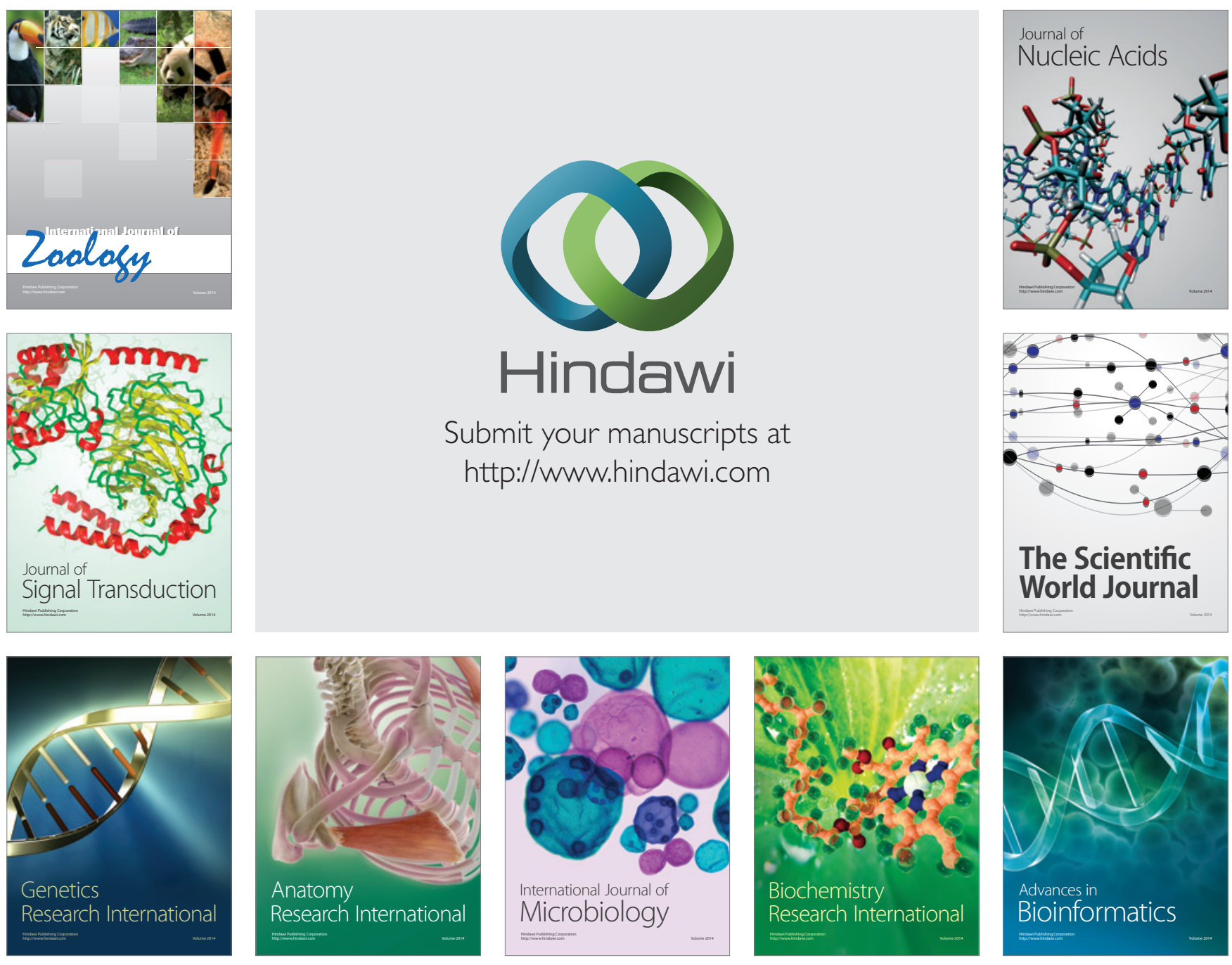

The Scientific World Journal
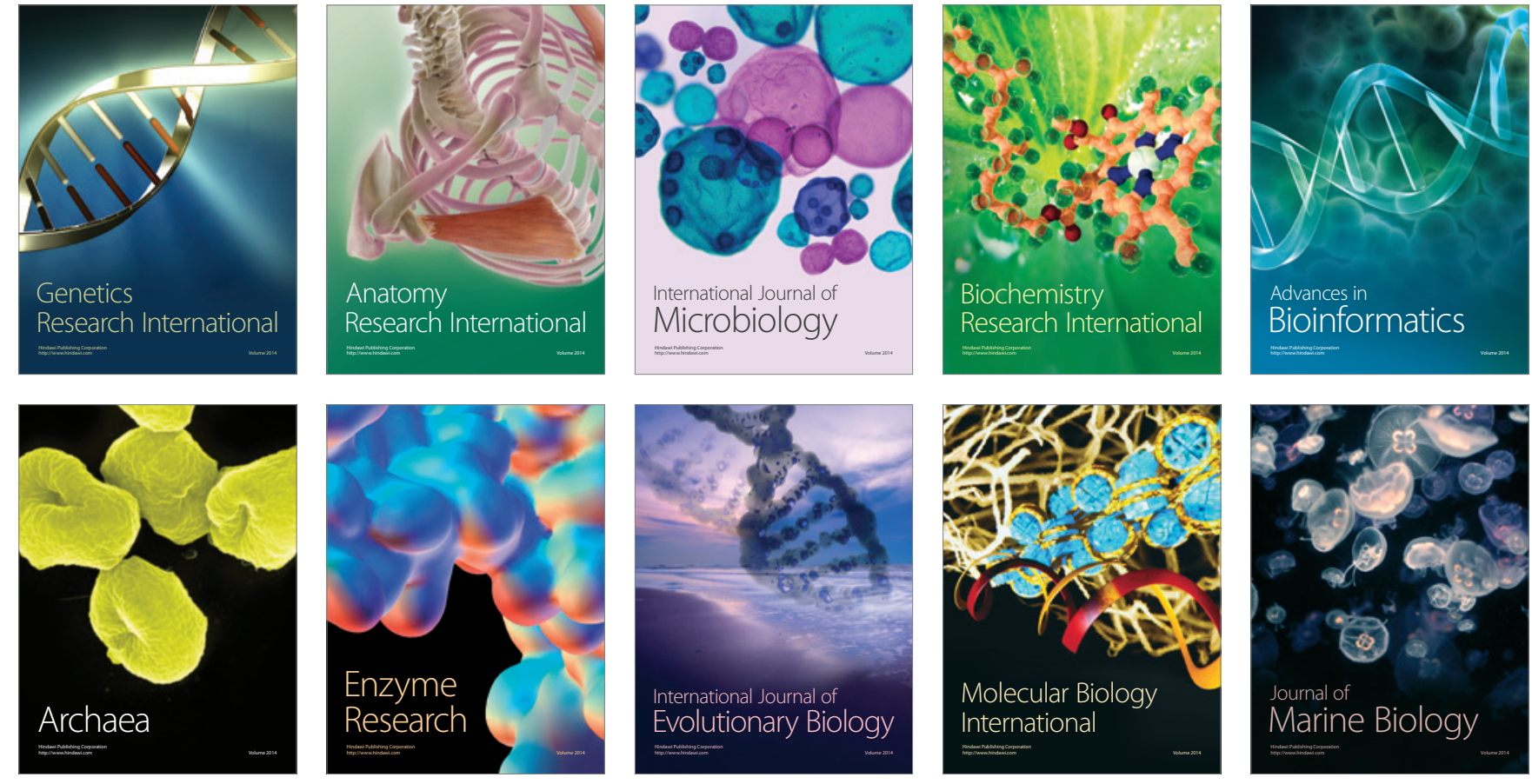